\title{
UMA NOVA ESPÉCIE DE EUTERPE (PALMAE - ARECOIDEAE - ARECEAE) DO BRASIL
}

\author{
Helio de Queiroz Boudet Fernandes*
}

Recebido em 3-12-89. Aceito em 28-3-90.

RESUMO - Euterpe espiritosantensis Fernandes é descrita e ilustrada a partir de co leções feitas no município de Santa Teresa, estado do Espírito Santo, sendo comparada com Euterpe edulis Martius, espécie dispersa nas florestas do leste do Brasil, com quem está relacionada. São feitas considerações sobre nomes vulgares, fenologia, ocorrência, habitat, usos e conservação.

Palavras-chave: Arecaceae, Palmae, Euterpe, palmito.

ABSTRACT - Euterpe espiritosantensis Fernandes is described and illustrated from collections in the municipality of Santa Teresa, state of Espírito Santo, as compared with Euterpe edulis Martius, a widespread species of eastern Brazil forests, to which is related. Considerations about common names, fenology, ocurrence, habitat, uses and conservation are made.

Key words: Arecaceae, Palmae, Euterpe, palmito.

Durante recentes trabalhos de campo como parte de levantamento florístico em curso no munić́pio de Santa Teresa, Estado do Espírito Santo, levandose em conta comentários de um conhecedor das matas da região a respeito da existência de um "palmito-vermelho", foram observados e coletados espécimens pertencentes ao gênero Euterpe Martius. O estudo destes revelou que reresentam uma espécie nova para a ciência, situada na seção Euterpopsis Becc. (Pinnata Barb. Rodr. - Burret, 1929).

Euterpe espiritosantensis Fernandes, sp. nov. - Figs. 1-2.

Caudex ad ca. $13 \mathrm{~m}$ altus. Foliorum vagina lutea, petiolo ca. $44 \mathrm{~cm}$ longo, pinnis parum irregulariter ordinatis. Inflorescentia ca. $90 \mathrm{~cm}$ longa, ramis dense pulverulentis ferrugineis ad badium, floribus masculis $6 \mathrm{~mm}$ longis, pistilodio trifido, fructibus $14 \mathrm{~mm}$ diam., albumine homogeneo.

* Museu de Biologia Mello Leitåo, Av. José Ruschi, 4, 29650, Santa Teresa, ES, Brasil. 
Holotypus. Brasil, Espírito Santo, Santa Teresa: Valsugana Velha. Estação biológica de Santa Lúcia, ca. $800 \mathrm{~m} / \mathrm{s} . \mathrm{m}$. Boudet-Fernandes 2564, Tabacow, Bausen e Molino, 23 set 1988 (MBML).

Paratypus. Brasil, Espírito Santo, Santa Teresa: Alto de Santo Antônio, ca. 800 m/s.m., Boudet Fernandes 2519 e Lucena, 9 set 1988 (MBML); Valsugana Velha, Estação Biológica de Santa Lúcia, Boudet Fernandes 2543, Bausen e Molino, 19 set 1988 (MBML, R); 1. c., Boudet Fernandes 2544, Bausen e Molino, 19 set 1988 (MBML, RB); 1.c., margem direita do rio Timbuí, ca. 750 m/s.m. Boudet Fernandes 2708 e Boone, 31 mar 1989 (MBML); l.c., margem esquerda do rio Timbuí, ca. $770 \mathrm{~m} / \mathrm{s} . \mathrm{m}$., Boudet Fernandes 2709, Boone e Molino, 5 abr 1989 (MBML, RB); 1.c., margem esquerda do rio Timbuí, ca. 790 m/s.m. Boudet Fernandes 2710, Boone e Molino, 5 abr 1989 (MBML, R); 1.c., margem esquerda do rio Timbuí, ca. 780 m/s.m. Boudet Fernandes 2711, Boone e Molino, 5 abr 1989 (MBML, BS); 1.c., margem esquerda do rio Timbuí, ca. 780 m/s.m. Boudet Fernandes 2712, Boone e Molino, 5 abr 1989 (MBML, $\mathrm{K})$.

Arborescente, ca. $15 \mathrm{~m}$ de altura, caule solitário castanho-acinzentado, longitudinalmente estriado, ca. $15 \mathrm{~cm}$ de diâmetro, rosado sub-corticalmente.

Folhas 9 a 14 contemporâneas, patentes e ereto-patentes, pouco deflexas para o ápice. Bainhas amarelas, obtuso-liguladas, ca. 1,2m de comprimento, esparsamente encobertas por pequenas escamas peltadas, aproximadamente elípticas, castanhas. Peciolo ca. $44 \mathrm{~cm}$ de comprimento, densamente coberto acima e abaixo com escamas castanhas, peltadas, de margens laceradas, até ca. $4 \mathrm{~mm}$ de comprimento, sobre uma fina camada cerosa, ambos posteriormente decíduos, deixando a superfície castanho-ponticulada. Raque vestida de forma semelhante, ao menos basalmente, $2,2 \mathrm{~m}$ de comprimento, com ca. de 70 pares de pinas medianamente pêndulas, um tanto irregularmente dispostas em intervalos de $1,2-5,5 \mathrm{~cm}$ (médias) e $0,7-23 \mathrm{~cm}$ (inferiores). Pina mediana com $106 \mathrm{~cm}$ de comprimento e $2,5 \mathrm{~cm}$ de largura (ate $3,2 \mathrm{~cm}$ na folha fresca), linear atenuada para $\mathrm{o}$ ápice acuminado, glabra superiormente, densamente encoberta interiormente com diminutas escamas peltadas castanhas e na nervura mediana com escamas basifixas, membranáceas, franjadas, castanhas, ate $8 \mathrm{~mm}$ de comprimento, com nervuras secundárias inconspícuas.

Inflorescência infrafoliar, ferruginea na floração passando a castanhoavermelhada na frutificação, ca. de $90 \mathrm{~cm}$ de comprimento. Prófilo e bráctea peduncular dorsiventralmente achatados, castanho-claros, subiguais, inseridos a $1 \mathrm{~cm}$ entre si: o primeiro ca. $104 \mathrm{~cm}$ de comprimento, dispersamente encoberto com escamas castanhas de margens laceradas, obtuso; a segunda, glabra, acuminada. Pedúnculo verde, basalmente, a amarelo, distalmente, ca. de $7 \mathrm{~cm}$ de comprimento, glabrescente, com camada cerosa delgada. Raque com brácteas castanhas de até ca. $28 \mathrm{~cm}$ de comprimento, densamente pulverulenta. ca. $57 \mathrm{~cm}$ de comprimento. Ráquilas ca. de 120 , ate $75 \mathrm{~cm}$ por $4,5 \mathrm{~mm}$, sub-roliças, densamente ferrugíneo-pulverulentas passando a castanho-avermelhadas na frutificação, de indumento persistente, com o bordo inferior das escavações florais 
obtuso-carnoso, apresentando membrana vestigial aguda de ca. $0,2 \mathrm{~mm}$ de altura; como na raque, apresentam escassa pilosidade associada ao indumento dominante.

Folha primordial palmadamente pinada. Plantas jovens, quando com caule aéreo, com bainhas escondidas pelas folhas secas tardiamente decíduas.

Flores inseridas, agrupada ou isoladamente, em escavações pouco profundas, com duas bractéolas palescentes de até $1 \mathrm{~mm}$ de altura, diminutamente franjadas, delimitando as femininas. Estaminadas purpurescentes, com $6 \mathrm{~mm}$ de altura; sépalas largo-triangulares, levemente carenadas, obscuramente agudas, ca. $2 \mathrm{~mm}$ de altura, alvo marginadas; pétalas assimetricamente ovado-oblongo-agudas; estames 6, ca. $4 \mathrm{~mm}$ de altura, com filetes firmes, alargados na base, não inflexos no ápice, ligeiramente mais curtos que as anteras que são estreitamente ovadas; pistilódio trífido, quase tão longo quanto os filetes. Pistiladas ocre, largamente ovadas, ca. $4,5 \mathrm{~mm}$ de altura; sépalas largamente arredondadas, obtusas, tenuemente carenadas, ca. $3 \mathrm{~mm}$ de altura; pétalas semelhantes, $1 \mathrm{~mm}$ maiores; ovário ovóide, ca. $3,5 \mathrm{~mm}$ de altura.

Fruto globoso, $14 \mathrm{~mm}$ de diâmetro, com a superfície diminutamente rugosa quando seco, com perianto persistente. Semente depresso-globosa, com endosperma homogêneo; embrião basilar, cônico, obtuso, $3,2 \mathrm{~mm}$ de altura por $2 \mathrm{~mm}$ de largura.

Esta espécie é afim de $E$. edulis pela semelhança quanto ao tamanho, forma e cor das flores, frutos e plântulas e pelo indumento pulverulento da inflorescência. Por estarem intimamente relacionadas e pelo fato de terem concentrações expressivas em áreas próximas, porém diferentes em termos de solo, acreditamos serem vicariantes edáficos. Entretanto, em situações pouco comuns as duas espécies foram observas lado a lado.

As observações detalhadas no campo e no herbário de Euterpe da região serrana do Espírito Santo conduziram-nos à diferenciação de dois grupos: um com caule branco-acinzentado, discretamente estriado, amarelado sub-corticalmente, 15-20 folhas contemporâneas, quase horizontalmente patentes, bainha predominantemente verde, folfolos regularmente distribuídas no raque e geralmente deflexos, inflorescência amarela na floração passando a cinzenta na frutificação, ráquilas facetadas, com margem inferior das escavações florais aguda e membranáceas a paleácea, plantas jovens, quando com caule aéreo, com bainhas foliares evidentes, apresentando menores concentrações em áreas de solo arenoso - Euterpe edulis (Martius, 1824, Mattos \& Matics, 1976 e Fernandes, obs. pess.); outro com as características correspondentes apresentadas no presente trabalho. - E. espiritosantensis.

Nomes vulgares. Palmito-vermelho, em alusão à cor dominante da inflorescência quando observada de longe; palmito-amarelo, em referência à cor da bainha; juçara e palmiteiro.

Fenologia. Floresce de setembro a novembro e frutifica cerca de seis meses após a floração.

Área de ocorrência. Parte NE da serra da Mantiqueira no estado do Espi- 
rito Santo. Encontrado apenas no município de Santa Teresa, localidades de Valsugana Velha, ca. 19033'W. Segundo informações populares ocorreu na localidade de Recreio, município de Santa Maria de Jetibá, encontrando-se extinta devido a destruição das matas.

Habitat. Forma manchas em florestas médias e baixas no alto de encostas, bordo superior de escarpas e fundo de vales, aproximadamente entre 700 e $1000 \mathrm{~m}$ de altitude, especialmente onde ocorre solo quartzítico-arenoso. Ocupa, quando adulta, o estrato arbóreo superior também aparecendo como emergente.

Usos. Informações de habitantes locais revelam que o seu palmito é comestŕvel e que o caule se presta à construção de casas rústicas (estuque). Sua beleza torna-a recomendável como planta de valor paisagístico.

Conservação. Encontra-se preservada na Reserva Biológica de Nova Lombardia (obs. pess.) e na Estação biológica de Santa Lúcia. Estas reservas foram os dois únicos locais onde a espécie foi encontrada em níveis populacionais expressivos. Consideramos este táxon dentro da categoria de conservação C ("Candidate") da IUCN (Dransfield et al., 1988) pois embora pareça raro e vulnerável, nossa avaliação é preliminar, necessitando de maiores informações de campo como verificação de sua distribuição e da possível redução da população pela exploração como fonte de palmito e/ou pela destruição de seus habitats.

Moore (1969) tece alguns comentários sobre o gênero e esboça dois grandes grupos baseando-se na coloração do indumento da inflorescência que em um é branco ou amarelo pálido - maior parte das espécies das terras baixas -, e em outro é amarelo camurça a ferrugíneo - cinco espécies endêmicas dos tepuis. Sob este ponto de vista, a espécie presentemente descrita estaria situada dentro do último grupo.

Matos \& Mattos (1976) citam a existência de três "variedades" de Euterpe edulis (não caracterizadas botanicamente como tal), conhecidas popularmente por palmeiteiro-branco, palmiteiro-vermelho e palmiteiro-macho ou encapado, diferenciáveis em diversos aspectos, entre os quais pela inflorescência e principalmente pela cor da bainha, para as duas primeiras e, para a última, por não se observar inflorescência e por apresentar o palmito encoberto por folhas secas. Sugerimos que a segunda e terceira "variedades" possam tratar-se de formas adultas e jovens, respectivamente, de E. espiritosantensis.

\section{Agradecimento}

Ao Museu de Biologia Mello Leitão - pró-Memória-Sphan-minC. À Orlando Perini, pela indicação da existência do palmito-vermelho na região; Frei José Corteletti pela revisão da diagnose latina; José W. Tabacow, pelo apoio, particularmente na parte fotográfica; Jorge Pedro Pereira Carauta, Ariane L. Peixoto, Andrew Henderson e Tânia Regatieri pelos comentários e revisão. Ao CNPq, cujo aux́lio permitiu-nos executar parte dos trabalhos de herbário. 


\section{Referências Bibliográficas}

BURRET, M. 1929. Die Gattung Euterpe Gaertn. Engler Bot. Jahrb., 63: 49-76.

DRANSFIELD, J., JOHNSON, D. \& SYNGE, H. 1988. The palms of the New World a conservation census. IUCN, Gland, Switzerland, and Cambridge, U.K. 44 p.

MARTIUS, C.F.P. VON. 1824. Historia Naturalis Palmarum, 2: 33, t. 32. Leipzig, T.C. Weigel.

MATTOS, M.D.L. de \& MATTOS, C.C.L.V. de. 1976. Palmito juçara-Euterpe edulis. Mart. - uma espécie a plantar, manejar e proteger. Brasil Florestal, 7: 9-20.

MOORE, H.E. 1969. Three new palms from Venezuela. Principes, 13: 137-141. 


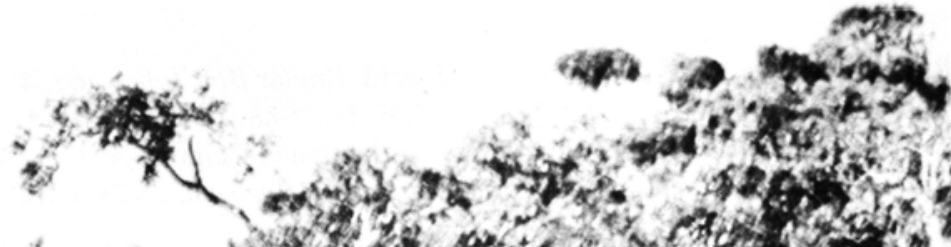

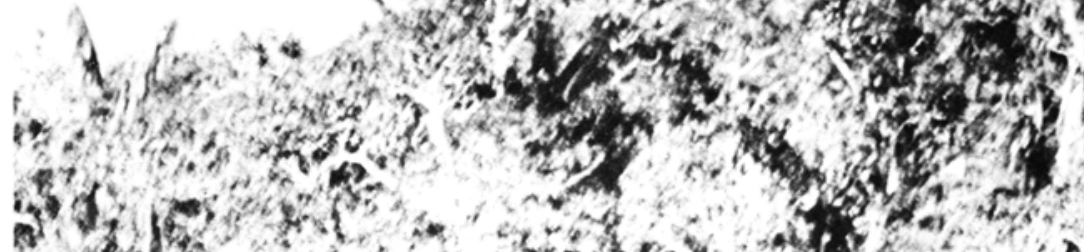
9.

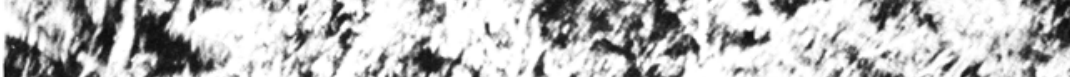
28.

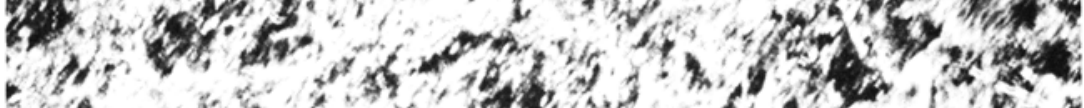

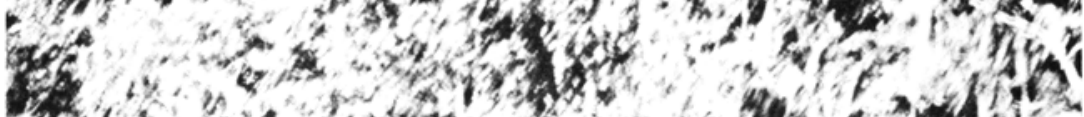

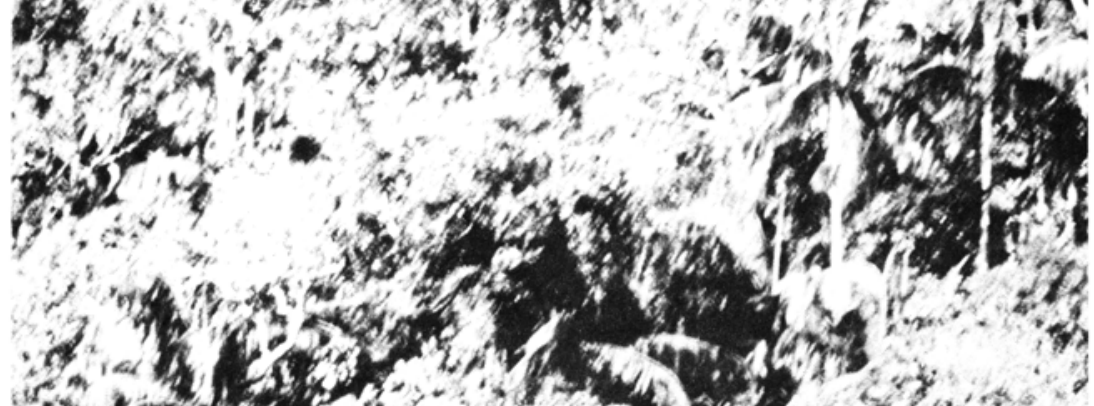

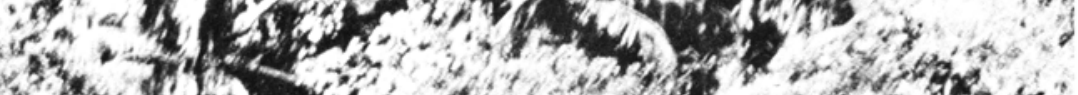
(n)

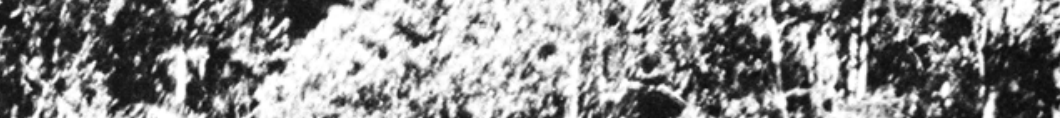

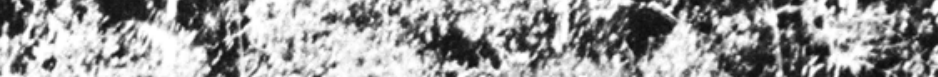

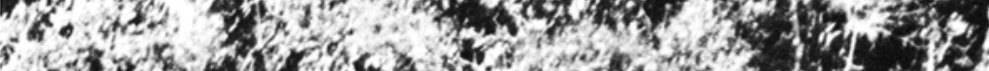

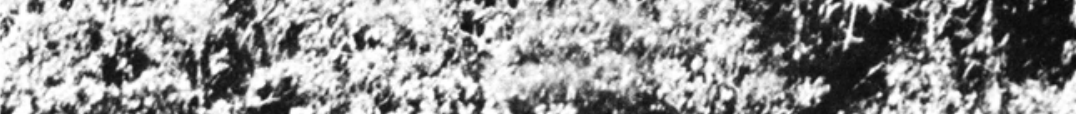

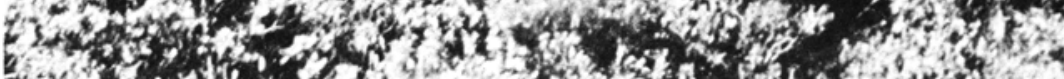

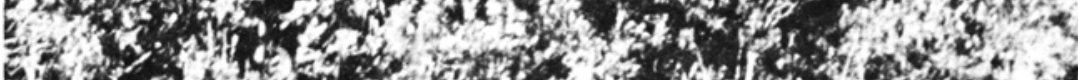
E.

FIGURA 1 - Euterpe espiritosantensis em seu habitat natural, na Estação Biológica de Santa Lúcia. Foto por J. Tabacow. 

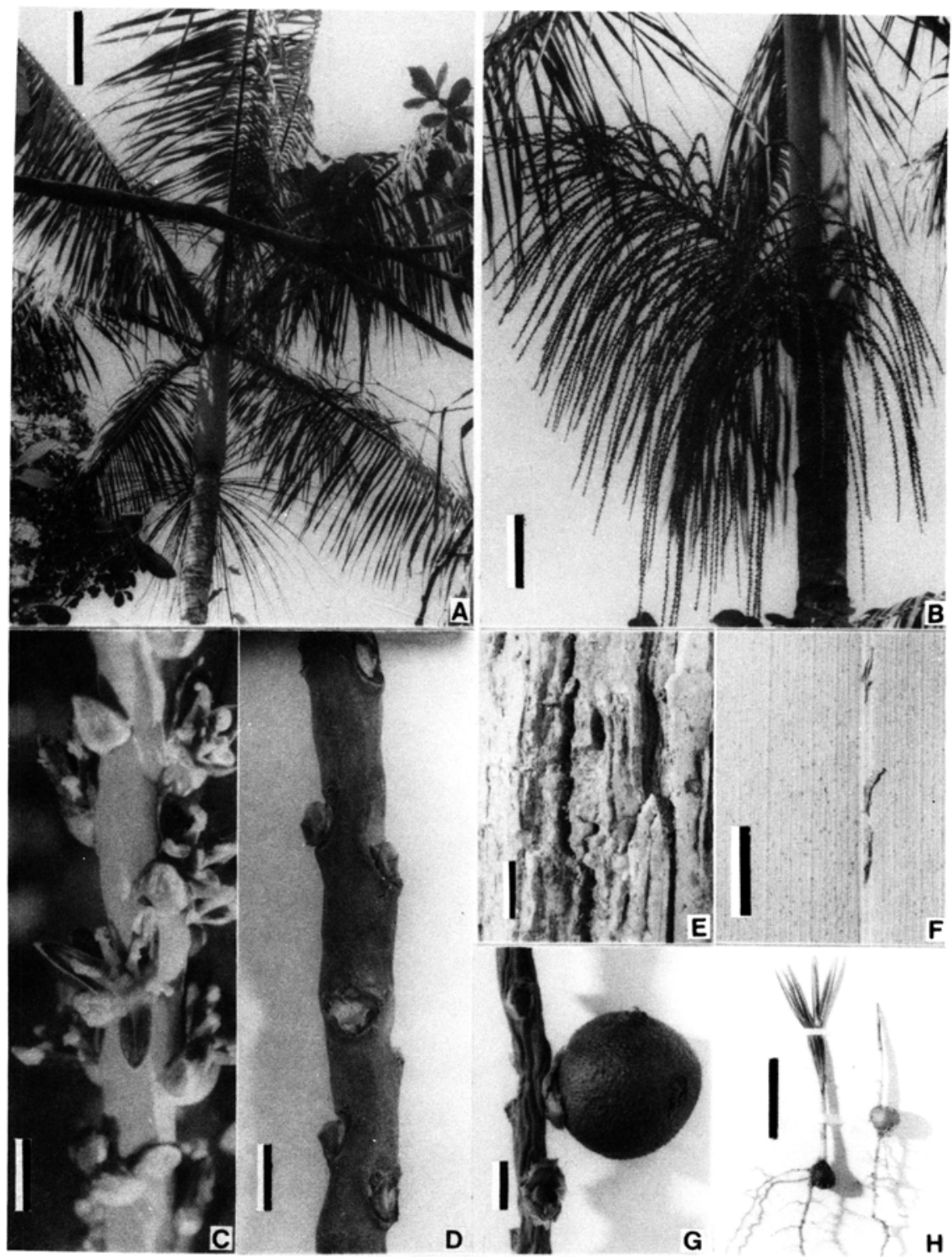

G

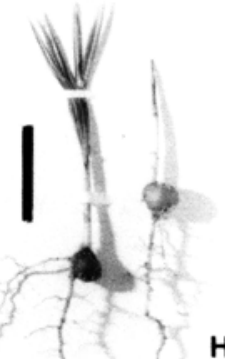

FIGURA 2 - Euterpe espiritosantensis. A - Aspecto geral da copa (escala = 50cm); $\mathrm{B}-$ Inflorescência (esc. $=20 \mathrm{~cm}) ; \mathrm{C}-$ Ráquila com flores femininas e masculinas $($ esc. $=$ $5 \mathrm{~mm}$ ); D - Ráquila com flores removidas (esc. $=5 \mathrm{~mm}$ ); $\mathrm{E}-$ Detalhe da casca (esc. $=$ $5 \mathrm{~mm}$ ); F - Detalhe do lado dorsal do folíolo (esc. $=5 \mathrm{~mm}$ ); $\mathrm{G}-$ Ráquila com fruto (esc. = $5 \mathrm{~mm}$ ); H - Plântulas (esc. $=5 \mathrm{~cm}$ ). Fotos: E, Fernandes 2519 et alii; C, D e F, Fernandes 2564 et alii; G, Fernandes 2709 et alii); por J. Tabacow. 